\title{
Genç Bireylerde Fiziksel Aktivitenin Akademik Başari Ve Depresyon Üzerine Etkisi
}

The Effect of Physical Activity on Academic Success and Depression in Young Individuals

\author{
Selen SEREL ARSLAN ${ }^{1}$, İpek ALEMDAROĞLU², Çiğdem ÖKSÜZ $Z^{3}$, Aynur Ayşe \\ KARADUMAN ${ }^{4}$, Öznur TUNCA YILMAZ \\ ${ }^{1}$ Dr. Fzt., Hacettepe Üniversitesi, Sağlık Bilimleri Fakültesi, Fizyoterapi ve Rehabilitasyon Bölümü, Ankara \\ ${ }^{2}$ Yrd. Doç. Dr., Hacettepe Üniversitesi, Sağlık Bilimleri Fakültesi, Fizyoterapi ve Rehabilitasyon Bölümü, Ankara \\ ${ }^{3}$ Doç. Dr., Hacettepe Üniversitesi, Sağlık Bilimleri Fakültesi, Ergoterapi Bölümü, Ankara \\ ${ }^{4}$ Prof. Dr., Hacettepe Üniversitesi, Sağlık Bilimleri Fakültesi, Fizyoterapi ve Rehabilitasyon Bölümü, Ankara
}

öz

Amaç: Çalışmanın amacı; genç bireylerde fiziksel aktivite düzeyinin akademik başarı ve depresyon üzerine etkisini belirlemektir. Gereç ve Yöntem: Katılımcıların yaş ve cinsiyet bilgileri kaydedildi. Akademik başarı için not ortalamaları sorgulandı. Fiziksel aktivite düzeyi, Uluslararası Fiziksel Aktivite Değerlendirme Anketi kısa formu kullanılarak belirlendi. Depresyon düzeyi ise Beck Depresyon Envanteri ile değerlendirildi. Sonuçlar: Çalışmaya \%69.3'ü kız olmak üzere yaş ortalaması 21.64 \pm 0.97 yıl olan 140 lisans düzeyinde olan genç birey katıldı. Katılımcıların akademik başarı ortalaması 2.98 \pm 0.41 , ve haftalık fiziksel aktivite ortalaması 2587.40 $\pm 2279.83 \mathrm{MET}$-dk/hafta'idi. Beck Depresyon Envanteri ortalama puanı $11.39 \pm 8.47$ 'idi. Fiziksel aktivite düzeyi ile akademik başarı arasında pozitif yönde, zayıf $(p=0.02, r=0.19)$ ve depresyon arasında negatif yönde, zayıf ilişki bulundu ( $p=0.01, r=-$ 0.21).Tartışma: Genç bireylerde fiziksel aktivite düzeyinin arttırılmasının akademik başarıyı artırma ve depresyonu azaltma üzerine olumlu etkileri olabileceği düşünülmektedir. Bu nedenle gençlerde fiziksel aktiviteyi teşvik eden olanakların sağlanması sağlıklı ve başarılı bir nesil için önemlidir.

Anahtar Kelimeler: Fiziksel aktivite; Akademik başarı; Depresyon; Genç

\section{ABSTRACT}

Purpose: The aim of this study was to determine the effect of physical activity level on academic success and depression in young individuals. Materials and Methods: The information including age and gender was recorded. The mean grade-point for academic success was questioned. Physical activity level was determined by using the short form of the International Physical Activity Questionnaire. The level of depression was assessed with the Beck Depression Inventory. Results: One hundred-forty young individuals at the undergraduate level with a mean age of $21.64 \pm 0.97$ years, of whom $69.3 \%$ were girls were included. The mean grade-point was $2.98 \pm 0.41$, and the mean weekly physical activity level of the participants was $2587.40 \pm 2279.83$ MET-min/week. The mean score of Beck Depression Inventory was $11.39 \pm 8.47$. A poor, positive correlation between physical activity level and academic degree $(p=0.02, r=0.19)$ and poor, negative correlation between physical activity level and depression ( $p=0.01, r=-0.25$ ) were found. Discussion: In conclusion, it is thought that increasing the level of physical activity of young individuals may have positive effects on academic achievement and reducing depression. Thus, provision of opportunities to promote physical activity in young ages is important for a healthy and successful generation.

Key Words: Physical activity; Academic success; Depression; Young 
Fiziksel aktivite; günlük yaşam içerisinde iskelet kaslarını kullanarak yapılan ve enerji harcaması ile sonuçlanan vücut hareketleridir. Oyun oynamak, ev işleri yapmak, yürümek, yemek yemek, banyo yapmak gibi günlük yaşam aktivitelerinin yanı sıra egzersiz ve spor da bu tanım kapsamında yer almaktadır (Sallis, Prochaska, Taylor, 2000).

Fiziksel aktivite sağlıklı yaşam için çok önemlidir. Çalışmalarda özellikle büyüme ve genç yetişkin dönemden itibaren fiziksel aktivitenin devam ettirilmesinin aerobik kapasite, kan basıncı, vücut kompozisyonu, glikoz metabolizması, iskelet sağlığı ve psikolojik sağlık üzerine olumlu etkileri olduğu bildirilmiştir (Riddoch, 1998; Sallis, 1994; Warburton, Nicol, Bredin, 2006). Fiziksel aktivite yetersizliği; kardiyovasküler sistem hastalıkları, obezite, diyabet gibi kronik rahatsızlıklar ve mental problemler için önemli bir risk faktörüdür (Lee, Shiroma, Lobelo ve ark, 2012; Danaei, Ding, Mozaffarian ve ark, 2009).

Gençlik yılları yetişkinliğe geçiş dönemi olarak düşünülebilir. Gençlik dönemi üniversite yıllarına denk gelmekte, ve bu bireylerin sosyal çevresinin büyük bir kısmını eğitim aldığı yerleşke, sosyal sorumluluğunun büyük bir kısmını ise eğitim gördüğü bölümün akademik yükümlülükleri oluşturmaktadır. Yer, zaman ve maddi kısıtıılıkların yanı sıra teknolojideki gelişmeler ile birlikte gençlerin fiziksel aktivite düzeyleri azalabilmektedir. Fiziksel aktivitenin sağlıklı yetişkin bireylerde sosyal ve kişisel başarıyı etkilediği (Faigenbaum, 2000; Van de Loo, Johnson, 1995), uyku kalitesi ve depresyon ile ilişkili olduğu yapılan çalışmalarda bildirilmiştir (Alapin, Fichten, Libman ve ark, 2000; Borodulin, Evenson, Monda ve ark, 2010; Işık ve ark, 2015). Bizim çalışmamızın amacı; fiziksel aktivite düzeyinin özellikle akademik başarı ve depresyon ile olan ilişkisini genç bireylerde ortaya koymaktır. Böylece gençlik döneminde akademik başarı üzerinde fiziksel aktivitenin yerinin belirleneceği ve genç, sağlıklı bireylerle çalışan terapistlere yol göstereceği öngörülmektedir.

\section{GEREÇ VE YÖNTEM}

Bu çalışma Hacettepe Üniversitesi, Sağıı Bilimleri Fakültesi, Fizyoterapi ve Rehabilitasyon Bölümü'nde gerçekleştirildi. Çalışmaya üniversite eğitimine devam eden lisans öğrencileri dahil edildi. Çalışma Dünya Tıp Birliği Helsinki Bildirgesi ilkelerine uygun olarak ilerletildi. Tüm katılımcılara araştırmanın içeriği ve amacı ile ilgili genel bilgi verildi ve araştırmaya katılmayı kabul eden, gönüllü kişilere onam formu imzalatılı. Mobiliteyi etkileyen herhangi bir kas iskelet sistemi problemi veya nörolojik hastalığı olan, çalışmaya katılmak istemeyen gençler çalışmaya dahil edilmedi.

Çalışmaya dahil edilen genç bireylerin boy uzunlukları ve vücut ağırlıkları ölçülerek kayıt edildi. Vücut ağırığı kalibre edilmiş dijital tartı kullanılarak kilogram $(\mathrm{kg})$ cinsinden kaydedildi. Ölçüm öncesi gençlerin üzerindeki ceket, hırka vb. giysiler, cüzdan, anahtarlık, cep telefonu, toka ve kemer vb. aksesuarlar ile ayakkabılarının çıkarılması sağlandı ve mümkün olan en hafif giysilerle ölçüm alındı. Boy uzunluğu duvara sabitlenmiş boy ölçer kullanılarak santimetre $(\mathrm{cm})$ cinsinden kaydedildi. Akademik başarı için çalışmaya dahil edilen öğrencilerin lisans not ortalamaları sorgulandı.

Katılımcıların fiziksel aktivite düzeyinin belirlenmesi için Türkçe versiyon çalışması, geçerliği ve güvenilirliği yapılmış olan Uluslararası Fiziksel Aktivite Değerlendirme Anketi kısa formu kullanıldı (Craig, Marshall, Sjöström ve ark, 2003; Öztürk, 2005). Bu anket yedi soru içermektedir ve yürüme, orta şiddetli, şiddetli aktivitelerde harcanan zaman ile oturmada harcanan zaman hakkında bilgi sağlamaktadır. Toplam skor hesaplanırken yürüme, orta şiddetli aktivite ve şiddetli aktivitenin süre (dakika) ve frekans (gün) toplamı kullanılmaktadır. Bu aktiviteler için standart MET değerleri oluşturulmuştur. Yürüme 3.3 MET, orta şiddetli fiziksel aktivite 4 MET, şiddetli fiziksel aktivite 8 MET ve oturma 1.5 MET olarak belirlenmiştir. $\mathrm{Bu}$ değerler kullanılarak haftalık fiziksel aktivite seviyesi hesaplandı. Örneğin; 3 gün 45 dakika yürüyen bir kişinin yürüme MET-dk/hafta skoru; 3.3 × 3 × $45=445.5$ MET-dk/hafta olarak hesaplanmaktadır. Fiziksel aktivite düzeyleri, MET hesaplamasının yanı sıra elde edilen sayısal verilere göre inaktif (<600 MET-dk/hafta), minimal aktif (600-3000 MET-dk/hafta) ve çok aktif (sağlık açısından yararlı olan) (>3000 MET-dk/hafta) şeklinde sınıflandırıldı.

Depresyon riskini ve depresif belirtilerin düzeyini belirlemek için Beck Depresyon Envanteri kullanıldı (Beck, Ward, Mendelson ve ark, 1961; Hisli, 1989). $\mathrm{Bu}$ envanter 21 maddeden oluşmaktadır ve her bir madde depresyonun şiddetine göre 0-3 arası puanlanmaktadır. Toplam alınan puan 0-63 arasında olmaktadır. Ölçek puan aralıkları 0-9 arasında ise depresyon olmadığını göstermektedir.10-16 puan hafif depresyonu, 17-24 puan orta düzey depresyonu, 25 ve üzeri puan şiddetli düzeyde depresyonu tanımlamaktadır. 


\section{İstatistiksel Analiz}

Verilerin istatistiksel değerlendirmesi, SPSS 20.0 istatistik paket programı kullanılarak yapıldı. Nitel veriler, sayı $(n)$ ve yüzde (\%) olarak verildi. Nicel veriler aritmetik ortalama (X), standart sapma (SS), alt ve üst değerler olarak hesaplandı. Fiziksel aktivite düzeyinin akademik başarı ve depresyon ile ilişkisi Spearman korelasyon katsayısı ile değerlendirildi. Fiziksel aktivite gruplarında akademik başarıyı gösteren not ve depresyon ölçeği ortalamaları arasındaki farklılı̆ın anlamlıı̆ına Kruskal Wallis Testi ile bakıldı. İstatistiksel anlamlılık değeri $p<0.05$ olarak kabul edildi.

\section{SONUÇ}

Genç bireylerde fiziksel aktivite düzeyinin akademik başarı ve depresyon ile ilişkisinin belirlenmesinde anlamlılık seviyesi 0.05 iken çalışmanın gücünün 0.80 olması için minimum örneklem genişliği 153 olması gerekir iken, çalışmamıza 140 genç bireyin gönüllü katılımı dolayısıyla güç 0.77 olarak belirlendi.

Çalışmaya katılan bireylerin \%69.3 ( $\mathrm{n}=97)^{\prime} \mathrm{u}$ kız ve \%30.7 $(n=43)$ 'si erkekti. Gençlerin tanımlayıcı özellikleri Tablo 1'de verildi.

Genç bireylerin fiziksel aktivite seviyeleri ve depresyon açısından etkilenim düzeyleri Tablo 2'de verildi.

Fiziksel aktivite düzeyi ile akademik başarı arasında pozitif yönde, zayıf ( $p=0.02, r=0.19)$ ve depresyon arasında negatif yönde, zayıf ilişki bulundu ( $p=0.01, r=-0.25$ ). Akademik başarı açısından inaktif ve minimal aktif gruplar arasında $(p=0.003)$, depresyon düzeyi açısından ise inaktif - minimal aktif ve inaktif - çok aktif gruplar $(p=$ $0.02)$ arasında anlamlı fark vardı $(p<0.001)$. Fiziksel aktivite düzeyine göre akademik başarı ve depresyon ölçeği ortalamaları ve gruplar arasındaki farklar Tablo 3'de sunuldu.

Tablo 1. Genç bireylerin tanımlayıcı özellikleri

\begin{tabular}{ccc}
\hline & $\mathbf{X}(\mathbf{S S})$ & min-max \\
\hline Yaş (yıl) & $21.64(0.97)$ & $18-23$ \\
Boy (cm) & $166.58(15.99)$ & $153-193$ \\
\hline Vücut ağırlığı (kg) & $61.84(10.73)$ & $42-96$ \\
\hline Akademik not (0-4) & $2.98(0.41)$ & $1.10-3.73$ \\
\hline Fiziksel aktivite düzeyi (MET-dk/hafta) & $2587.40(2279.83)$ & $0-10.986$ \\
\hline Beck depresyon envanteri (0-63) & $11.39(8.47)$ & \\
\hline
\end{tabular}

Tablo 2. Gençlerin fiziksel aktivite ve depresyon açısından etkilenim düzeyleri

$\begin{array}{lll}\text { Etkilenim düzeyleri } & \mathbf{n} & \%\end{array}$

Fiziksel aktivite düzeyi

\begin{tabular}{ccc}
\hline İnaktif (<600 MET-dk/hafta) & 38 & 27.1 \\
\hline Minimal aktif (600-3000 MET-dk/hafta) & 81 & 57.9 \\
\hline Çok aktif (>3000 MET-dk/hafta) & 21 & 15
\end{tabular}

\section{Depresyon düzeyi}

\begin{tabular}{ccc}
\hline Normal (0-9) & 67 & 47.9 \\
\hline Hafif depresyon (10-16) & 40 & 28.6 \\
\hline Orta depresyon (17-24) & 24 & 17.1 \\
\hline Şiddetli depresyon (25-63) & 9 & 6.4 \\
\hline
\end{tabular}


Tablo 3. Fiziksel aktivite düzeyine göre akademik başarı ve depresyon düzeyi ortalamaları

\section{Akademik başarı Beck depresyon}

Fiziksel aktivite düzeyi

\begin{tabular}{lc}
\cline { 2 - 2 } & $\mathbf{X}(\mathbf{S S})$ \\
\hline İnaktif & $2.77(0.55)$ \\
\hline Minimal aktif & $3.06(0.33)$ \\
\hline Çok aktif & $3.03(0.28)$
\end{tabular}

\section{TARTIŞMA}

Gençlik dönemi, yaşam ile ilgili alışkanlıkların belirginleştiği ve yetişkinlik dönemine geçiş olarak düşünüldüğünde kritik bir süreçtir. Bu nedenle gençlik döneminde fiziksel aktivite düzeylerinin belirlenmesi gençlerin, ailelerin ve eğitim verenlerin bu konudaki farkındalığını arttırma ve bu doğrultuda yönlendirmelerin yapılması açısından önemlidir. Bu sebeplerle çalışmamızda 18-24 yaş arası genç bireylerin fiziksel aktivite düzeyinin belirlenmesi ve akademik başarı ve depresyon durumları ile olan ilişkisinin saptanması amaçlandı. Çalışmamıza göre lisans eğitimine devam eden gençlerin yalnızca \%15'inin yeterli düzeyde aktif olduğu ve \%52.1'inin çeşitli düzeylerde depresyon tanımladığı belirlendi. Fiziksel aktivite düzeyi ile akademik başarı ve depresyon düzeyinin ilişkili olduğu ve fiziksel aktivite düzeyi arttıkça öğrencilerin akademik başarı düzeylerinin arttığı, depresyon düzeylerinin düştüğü bulundu.

Çalışmamızda lisans eğitimine devam eden genç bireylerin aktivite düzeylerinin oldukça düşük olduğu ve yarısında hafiften şiddetliye depresyon tanımlandığı belirlendi. Literatürdeki benzer çalışmalara bakıldığında; üniversite öğrencilerinde yapılan bir çalışmada fiziksel aktivite düzeylerinin orta düzeyde aktif olduğu, uyku kalitelerinin kötü olduğu ve depresyonlarının olmadığı (Işık, Özarslan, Bekler, 2015) bildirilmiştir. Literatürdeki çalışmalar ve bizim çalışmamızda; gençlerin büyük bir kısmının fiziksel aktivite düzeyinin yetersiz olduğu belirlendi. Bu sonuçlar akademik eğitim gören gençlerin fiziksel aktivite ile ilgili farkındalıklarının arttırıması, bu konuda gerekli yönlendirmelerin yapılması ve gençlerin fiziksel aktivite düzeylerinin arttırılması konusunda teşvik edilmesinin gerekliliğini ve önemini ortaya koymaktadır.

Çalışmamızda genç bireylerin fiziksel aktivite düzeyi ile akademik başarı ve depresyon düzeyinin p envanteri

p X (SS)

$15.89(9.66)$
$0.009^{*}$$\quad 0.001^{*}$

zayıf da olsa ilişkili olduğu, fiziksel aktivite düzeyi arttıkça gençlerin akademik başarılarının artabileceği ve depresyon düzeylerinin düşüş gösterebileceği gözlendi. Literatürde yer alan çalışmalara bakıldığında birçok araştırmada da bizim çalışmamızın sonuçlarını destekler biçimde farklı öğrenim düzeylerindeki gençlerde de fiziksel veya sportif aktivitelerin akademik başarıyı etkilediği bulunmuştur (Singh, Uijtdewilligen, Twisk ve ark, 2012; Whitley, 1999; Linder, 1999; Saygılı, Atay, Eraslan ve ark, 2015; Öcal, Settar Koçak, 2010). Örneğin; 2010 yılında ortaöğretim düzeyindeki öğrenciler ile yapılmış bir çalışmada okul sporlarına katılan öğrencilerde genel not ortalamalarının daha yüksek olduğu saptanmıştır (Öcal ve ark, 2010). Aynı zamanda literatür fiziksel aktivite ve depresyon arasındaki ilişki konusunda da çalışmamızın sonuçlarını desteklemektedir (Işık ve ark, 2015; Tekin, Amman, Tekin, 2009; Cao, Qian, Weng ve ark, 2011). Ayrıca üniversite öğrencileri ile yapılan bir başka çalışmada iki ay süren egzersiz programına katılan bireylerin depresyon düzeylerinde gelişme kaydedildiği saptanmıştır (Tekin ve ark, 2009). Çalışmamızda fiziksel aktivite düzeyi yeterli olan gençlerin akademik başarılarının daha yüksek ve depresyon düzeylerinin daha düşük olabileceği bulgusunun; kendilerini fiziksel olarak daha sağlıklı ve mutlu hissetmeleri, günlük yaşam ile ilgili streslerini daha iyi tolere edebilmeleri, disiplin duygularının gelişmiş olması, günlük planlamalarını daha iyi yapabilir durumda olmaları gibi birçok etmene bağlı olabileceğini düşünmekteyiz.

Sonuç olarak, fiziksel aktivite düzeyi yeterli olan genç bireylerin depresyon düzeylerinin daha düşük ve akademik başarılarının daha yüksek olması eğilimi aileler ve toplum açısından önemli bir bulgu olup, çocukların daha küçük yaştan itibaren fiziksel aktivitelerinin arttırılması ve spor yapma alışkanlığı kazandırılması yönünde desteklenmeleri gerektiği 
sonucunu ortaya koymaktadır.

Teşekkür: $\mathrm{Bu}$ çalışma Hacettepe Üniversitesi Sağlık Bilimleri Fakültesi Fizyoterapi ve Rehabilitasyon Bölümü IV. sınıf öğrencilerinin Koruyucu Fizyoterapi ve Rehabilitasyon Dersi kapsamında gerçekleştirilmiştir. Öğrencilerimize ve çalışmamıza gönüllü olarak katılmayı kabul eden lisans öğrencilerine teşekkür ediyoruz. Bu çalışma herhangi bir burs/fon alınmadan gerçekleştirilmiştir.

\section{Kaynaklar}

Alapin, I., Fichten, C. S., Libman, E., Creti, L., Bailes, S., \& Wright, J. (2000). How is good and poor sleep in older adults and college students related to daytime sleepiness, fatigue, and ability to concentrate?. J Psychosom Res, 49(5), 381-390.

Beck, A. T., Ward, C. H., Mendelson, M., Mock, J., \& Erbaugh, J. (1961) An Inventory for measuring depression. Arch of Gen Psychiatry, 4(6), 561-571.

Borodulin, K., Evenson, K. R., Monda, K., Wen, F., Herring, A.H., \& Dole, N. (2010). Physical activity and sleep among pregnant women. Paediatr Perinat Epidemiol, 24(1), 45-52.

Cao, H., Qian, Q., Weng, T., Yuan, C., Sun, Y., Wang, H., \& Tao, F. (2011). Screen time, physical activity and mental health among urban adolescents in China. Preventive Medicine, 53(4-5), 316-320.

Craig, C. L., Marshall, A. L., Sjöström, M., Bauman, A. E., Booth, M. L., Ainsworth, B. E.,\& et al. (2003). International physical activity questionnaire: 12-country reliability and validity. Med Sci Sports Exerc, 35(8), 1381-1395.

Danaei, G., Ding, E. L., Mozaffarian, D., Taylor, B., Rehm, J., Murray, C. J., \& Ezzati, M. (2009). The preventable causes of death in the United States: comparative risk assessment of dietary, lifestyle, and metabolic risk factors. PLoS Medicine, 6(4), e1000058.

Faigenbaum, A. D. (2000). Strength training for children and adolescents. Clin Sports Med, 19(4), 593-619.

Hisli, N. (1989). Beck Depresyon Envanterinin üniversite öğrencileri için geçerliği güvenirliği. Psikoloji Dergisi, 7 , 3-13.

Işık, Ö., Özarslan, A., \& Bekler, F. (2015). Üniversite öğrencilerinde fiziksel aktivite uyku kalitesi ve depresyon ilişkisi. Niğde Üniversitesi Beden Eğitimi ve Spor Bilimleri Dergisi, 9, 65-73.

Lee, I. M., Shiroma, E. J., Lobelo, F., Puska, P., Blair, S. N., Katzmarzyk, P. T., \& et al. (2012). Effect of physical inactivity on major non-communicable diseases worldwide: an analysis of burden of disease and life expectancy. Lancet, 380(9838), 219-229.

Linder, K. J. (1999). Sport participation and perceived academic performance of school children and youth. Pediatr Exerc Sci, 11(2), 129-143.

Öcal, K., \& Settar Koçak, M. (2010). Okul sporlarının orta öğretim öğrencilerinin akademik başarı ve davranış gelişimine etkisi. Akdeniz Eğitim Araştırmaları Dergisi, (7), 89-94.

Öztürk, M. (2005). Üniversitede eğitim-öğretim gören öğrencilerde Uluslararası Fiziksel Aktivite Anketinin geçerliliği ve güvenirliği ve fiziksel aktivite düzeylerinin belirlenmesi (Yüksek Lisans Tezi). Hacettepe Üniversitesi/ Sağlık Bilimleri Enstitüsü, Ankara.

Riddoch, C. (1998). Relationships between physical activity and health in young people. In S. Biddle, N. Cavill \& J. F. Sallis (Eds.), Young and active?: Young People and health-enhancing physical activity- Evidence and implications (pp.17-49). London: Health Education Authority.

Sallis, J. F. (1994). Determinants of physical activity behavior in children. In R.R. Pate \& R.C. Hohn (Eds.), Health and fitness through physical education (pp.31-43). Champaign, IL: Human Kinetics.

Sallis, J.F., Prochaska, J.J., \& Taylor, W.C. (2000). A review of correlates of physical activity of children and adolescents. Med Sci Sports Exerc, 32(5), 963-975.

Saygılı, G., Atay, E., Eraslan, M., \& Hekim, M. (2015). Düzenli olarak spor yapan ve yapmayan öğrencilerin kişilik özellikleri ile akademik başarıları arasındaki ilişkinin incelenmesi. Kastamonu Eğitim Dergisi, 23(1), 161-170.

Singh, A., Uijtdewilligen, L., Twisk, J. W., van Mechelen, W., \& Chinapaw, M. J. (2012). Physical activity and performance at school: a systematic review of the literature including a methodological quality assessment. Arch Pediatr Adolesc Med, 166(1), 49-55.

Tekin, G., Amman, M. T., \& Tekin, A. (2009). Serbest zamanlarda yapılan fiziksel aktivitenin üniversite öğrencilerinin depresyon ve atılganlık düzeylerine etkisi. Uluslararası Insan Bilimleri Dergisi, 6(2), 148-159.

Van de Loo, D.A., \& Johnson, M. D. (1995). The young female athlete. Clin Sports Med, 14(3), 687-707.

Warburton, D. E., Nicol, C. W., \& Bredin, S. S. (2006). Health benefits of physical activity: the evidence. CMAJ, 174(6), 801-809.

Whitley, R. L. (1999). Those dumb jacks are it again: A comparison of the educational performances of athletes and nonathletes in North Carolina High Schools from 1993 through 1996. High Sch J, 82(4), 223-233. 
